\title{
Planning Agricultural Enterprises with the Integration of Environmental Effect Interaction and GHG Calculations
}

\author{
Attila Kovacs ${ }^{1}$, Csaba Fogarassy ${ }^{2}$ \\ ${ }^{1}$ Szent Istvan University, Institute of Business Studies, Godollo, Hungary \\ ${ }^{2}$ Szent Istvan University, Climate Change Economics Research Centre, Godollo, Hungary \\ Email address: \\ kovacs.attila@gtk.szie.hu (A. Kovacs), fogarassy.csaba@gtk.szie.hu (C. Fogarassy)
}

\section{To cite this article:}

Attila Kovacs, Csaba Fogarassy. Planning Agricultural Enterprises with the Integration of Environmental Effect Interaction and GHG Calculations. Science Journal of Business and Management. Vol. 3, No. 1, 2015, pp. 33-42. doi: 10.11648/j.sjbm.20150301.15

\begin{abstract}
The clarification of the theoretical questions pertaining to the planning of agricultural enterprises is imperative in realizing the goals of the input-transformation-output relation. We also can not disregard pinning theory against actual use, meaning the inclusion of limitations in agricultural corporate practice. Scientifically well-prepared processes can go to waste if their limitations have not been evaluated as a result of the absence of information on implementation, theoretic unpreparedness, lack of motivation, or other various reasons. Therefore, in our analyses, we would also like to devote some time to the feasibility of planning and the outlining of planning methods useful for actual practice via actual plant inspections. During the planning phase, extreme difficulties may arise in the form of including environmental effects and making the impacts of the entrepreneur's decisions on the environment felt. Modeling these environmental and climate interactions and including them in planning models are the focus of this examination. The analyses were conducted at the Experimental Farm of Szent Istvan University in Hungary, which has served as the background of different plant economy analyses since 1992. Our experiences, including more than ten years of planning, preparation of decisions, and analysis in the experimental farm, allow us to draw many useful conclusions.
\end{abstract}

Keywords: GHG Calculations, Agricultural Enterprises, Input-Transformation, Input-Transformation-Output, Corporate Planning, Cost Benefit Analysis, IPCC, Livestock Simulation, Linear Programming, Scenario Planning

\section{Introduction}

In addition to know how the economic system works and the effect mechanisms of external factors, it is also extremely important to know the magnitudes and influence levels of the actual impact factors in the process of preparing the decisions of various enterprises. The basis required for this is made up by the input-transformation-output relations defined by the methodology. In this relation, the analysis of the input-transformation side is extremely important because in most cases a large amount of inputs is required to produce the output (product or service), not to mention the fact that they are needed in various combinations to allow the creation of the designated output. Regarding economic efficiency, the effectiveness of economic processes has a defining role in what amounts and combinations of inputs are used in processing the actual products or services. Naturally, the goal to be envisioned is always the effective operation of the system in its entirety; however, the input-conversion side, meaning the analysis of costs, is what requires the most significant portion of tasks in decision preparing. Due to the above reasons, we defined the goal of our analyses to be the detailed exploration of cost analysis and making its role in preparing decisions clear.

In the field of agricultural enterprises, we meet many specialties, which make the preparation of decisions much harder. On the one hand, natural factors (e.g. climatic or climate effects), biological factors (e.g. the reproduction or growth processes of creatures), and their organizational consequences (immovability, seasonality, risks, etc.) increase the amount of time required for the preparation of decisions, and, on the other hand, they decrease the effectiveness and precision of said decisions when compared to more controlled economic processes. Therefore, specific procedures and methods are often necessary for preparing the decisions of agricultural enterprises. In light of this, we will also try and evaluate, or in some cases further develop, some of these specific analysis methods. As the most important task of corporate governance, corporate planning collects the steps of preparation of decisions, which influence the overall operation of an enterprise and how its future will play out. A type of 
corporate planning that meets today's expectations is impossible to realize without cost analysis, which makes planning decisions possible. The cost analysis related to planning presumes routine procedures, since most of the plan decisions are repeated annually [5]. Also, in the case of more drastic changes in the external environment, the need for specific planning and cost analysis methods or run-downs may also surface, which are part of strategic governance (strategic management). During these analyses, the role of forecasts as well as information and decisions that influence the future become more important, which in turn requires the application of complex planning methods.

\section{Methodology}

In the course of our analysis, we concentrated primarily on how corporations function. The characteristics of natural resources cannot be excluded from the processes of planning and preparation of decisions, since the proper management of these fundamentally defines the efficiency of the enterprise. Therefore, there is a need for an outlook and information base to manage problems, which is applicable to creating and evaluating information required for making the proper decision. The information base of my research was the data collection system created at the Experimental Farm of Szent Istvan University. The data processed here was subjected to primary evaluation, mostly in a cost relation, followed by a result relation to a lesser degree. During the research, the input-conversion-output connection system was stressed, especially in regards to the connection between crop production and husbandry. Our analyses aim to shed light on the impact factors of a complex, mixed-profile agricultural enterprise's processes of planning and decision preparation, which is why we tried to create a framework that can manage changes simultaneously in material flow, activity and financial processes. An important point was for the system to include decisions in the presence of uncertainty, which is very typical of the decisions of agricultural enterprises. All these aspects lead to the creation of a complex model, which made it possible to highlight more important factors via the Pareto principle as well as by means of the system-centered and decision-centered grouping of costs, which factors were later put in focus. After that, using the cost-benefit analysis was used to calculate the effects of the decisions made by the enterprise, in a way that both positive and negative impacts are present. Finally, using the methodology of the Intergovernmental Panel of Climate Change (IPCC) [6] and an operation research method, we summarized the planning model into a unified system that enables the analysis of assumptions related to future changes and the effects their answers have on income.

\section{Results}

\subsection{Characteristics of Cost Analysis Regarding Agricultural Enterprises}

In our analyses, we introduce the opportunities of dividing costs into groups via various criteria. Of these, we highlighted the grouping which embodies a mixture of practice and theory, which shows that we cannot strictly adhere to accounting theory during planning and decision making, especially in situations that are classified as hard to structure kind of problems.

Table 1. Costs grouped according to decision and eligibility.

\begin{tabular}{llll}
\hline & & Dependence on decision maker & \multicolumn{1}{c}{ Fix } \\
\hline \multirow{2}{*}{ Dependence on accountability of costs } & Direct & Variable & Direct constant \\
& Indirect or reduced & Reduced variable & Reduced constant \\
\hline
\end{tabular}

Source: self-made

In this grouping, the views of accounting and plant economy are mixed. The total costs are as follows:

$\mathrm{TC}=\mathrm{VC}+\mathrm{FC}=\left(\mathrm{VC}_{\text {direct }}+\mathrm{VC}_{\text {indirect }}\right)+\left(\mathrm{FC}_{\text {direct }}+\mathrm{FC}_{\text {indirect }}\right)$

This equation can also be used as a fundamental element in process-based cost management. The costs related to various enterprise processes and activities can be classified into this category, depending on how much they are represented in the total costs related incurred during the activities. After the categorization, in order to raise the effectiveness of the results, we can decide what inputs are to be dealt with primarily (Table $1)$.

To plan costs, it is useful to mix the above mentioned grouping opportunities in various combinations. This means that in accordance with the Pareto principle, we have to map which "A" category costs are noteworthy, which need highlighting, or which are to be managed separately during the detailed planning of costs. In case of the "B" category, it is a matter of decision whether the actual cost can be automated via some method or whether we should use a cost-change variable during our calculations.

Enterprises have to have a return during product realization on a scale that covers:

- the total costs of resource requirement and usage, also

- the management costs of resources which are mandatorily kept on inventory but were not used during the planning phase, and

- in addition to the above, also offers a profit that makes the use of resources for the determined goal economically valid.

Expenditures are refunded analytically in the prices of the various products. During the planning process, the only costs which are in direct relation to the production plan are the variable costs. Between the price of the product and these costs, there has to be a margin, a so-called cover, which can 
proficiently support the non-plannable fixed costs by product, while simultaneously able to generate profits for the enterprise. Accounting likes to use the differentiation analyses beyond cover calculations. The goal of these analyses is to show the reasons for differences between the plan and the actual facts.
Relevant literature differentiates this kind of analysis into four different groups: cost, quantity, selection, and quality selection differentiations. Figure 1 shows the result of a cost analysis by structuring possibilities.

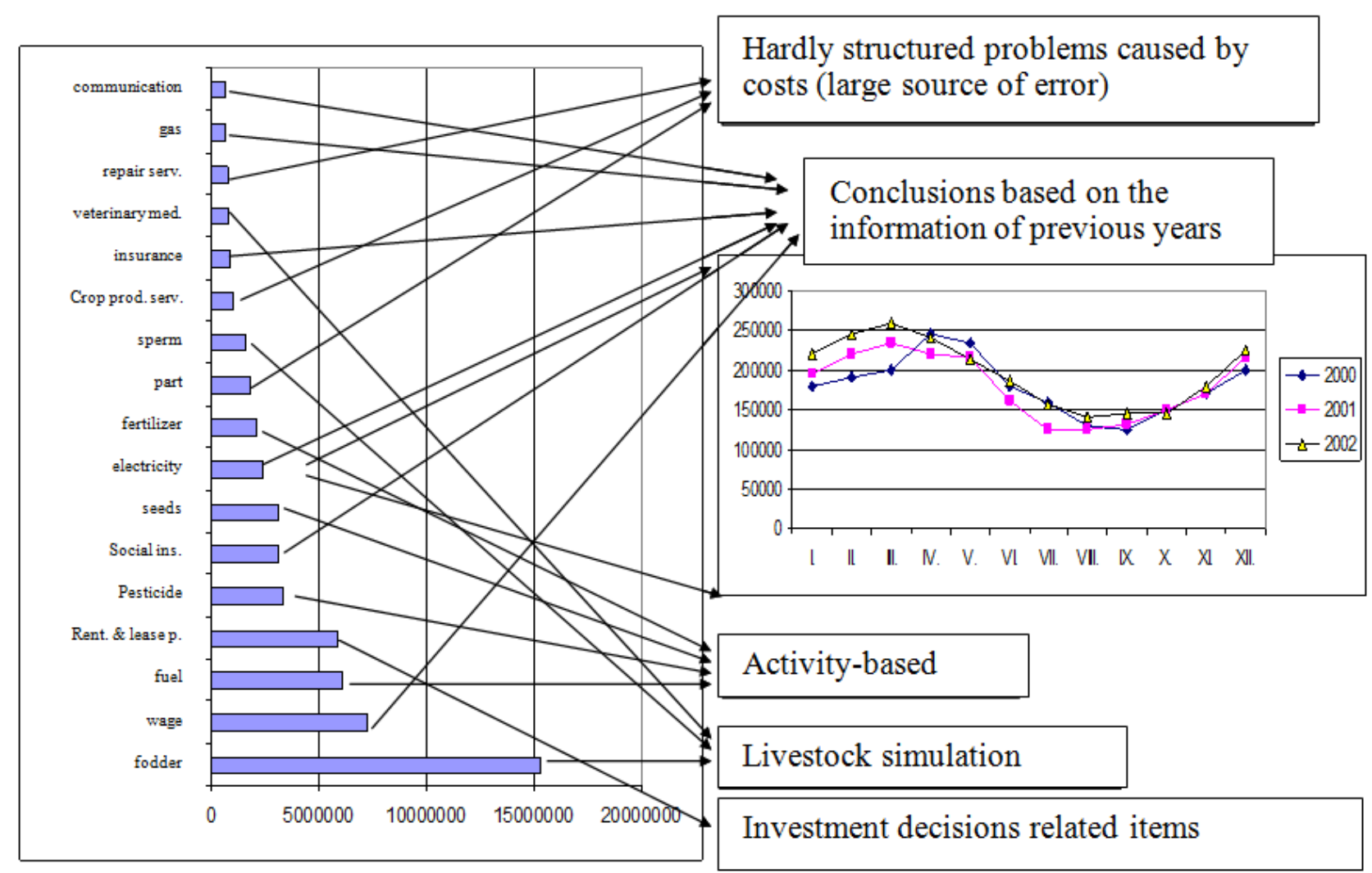

Figure 1. Analysis of costs by how much they can be structured.

Generally, we can say that cost analyses can have a high level of fluctuation and uncertainty. This is due to the characteristics of biological systems on the one hand and the exposedness of the sector and improper regulations on the other. Therefore, the analyses highlight the factors that influence the annual results of various sectors but they can not help in identifying the reasons behind them. Of the possible economic analyses and evaluations, we performed the evaluation of precision farming and the economic evaluation of a technological transition to using a milking robot.

\subsection{Cost-Benefit Analysis During Evaluation of Transition to Precision Farming}

From an economic standpoint, precision farming can be evaluated on the basis of the criteria we are already familiar with from technological development. The difference may mostly be that, while previous attempts at technological development mainly focused on replacing human labor with more effective technological and biological processes, precision farming is based on replacing traditional methods that use mostly homogenous agronomical processes with a new, more developed, and localized production technology alternative - mainly built on the foundations of communication technology and information technology.

The following basic analytical tasks were to be solved regarding the precision farming:

- modeling the system of precision farming,

- acquiring the extra information on production locations and evaluating its economic viability,

- re-defining cost-benefit connections (production functions) from the viewpoint of precision farming,

- defining models and algorithms which calculate the optimal quantities of the applied factors,

- including economic factors into economic calculations,

- developing models which calculate the revenue generated by the transition to precision farming,

- evaluating the size-efficiency questions of precision farming.

To clear up all these questions, we have to shed light on the cost-benefit connections of the various tables and subdivisions in a detailed manner, and we also have to draw conclusions based on the results. During the outlining of previous analyses, SZÉKELY et al. (2000) had the goal of including only those few factors into their calculations that change the economic 
value compared to traditional methods. The following generic equation was defined for the calculation of this extra income:

$$
\mathrm{NEI}_{\mathrm{cv}}=-(\mathrm{IC}-\mathrm{DC})+(\mathrm{SR}-\mathrm{EC} \pm \mathrm{IE}) \frac{q^{n-1}}{q-1}
$$

where:

$\mathrm{NEI}_{\mathrm{cv}}=$ net present value of extra income

$\mathrm{IC}=$ surplus investment costs of equipment to be acquired

$\mathrm{DC}=$ possible subsidies and discounts

$\mathrm{SR}=$ surplus revenue resulting from the extra yield and the effects of quality improvement resulting from the use of the precision farming system

$\mathrm{EC}=$ the balance of extra costs and possible savings of the precision farming system

$\mathrm{IE}=$ indirect economic effects of using the precision farming system

$\mathrm{q}=$ interest rate factor

$\mathrm{n}=$ number of years (lifespan)

Using this simple calculation, the return on investment cost (IC - DC) is calculated by comparing it to the annually unchanging economic advantages and their recalculation to present values. (The recalculations must be performed by multiplying the annuities with the factor that enables the

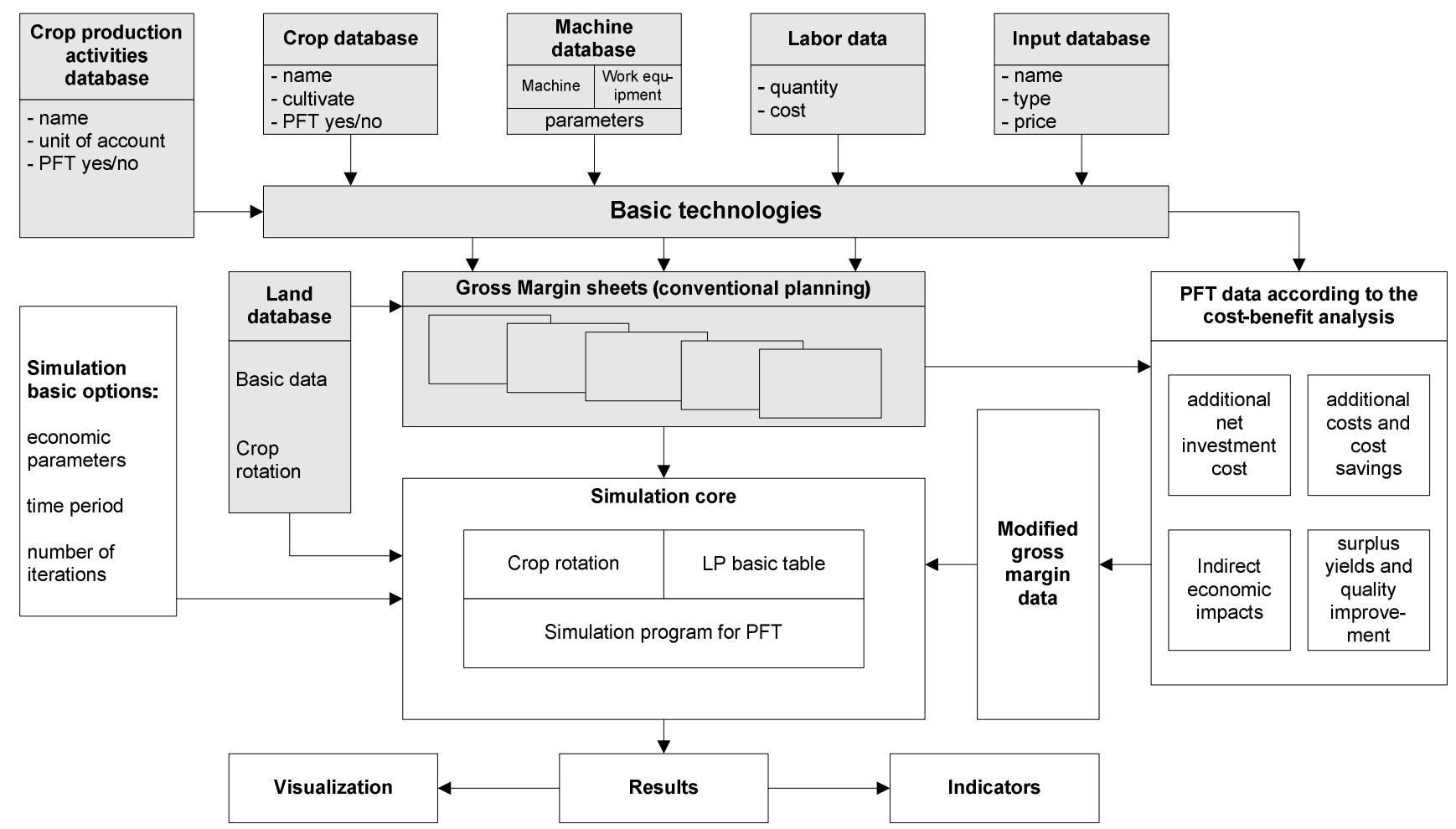

Figure 2. The process diagram of the model evaluating the precision farming at University Farm.

Source: self-made

As a summary, we can state that the economic interpretation of precision farming is a difficult problem. We can only define the surplus pros and cons that affect the efficiency of the farming by means of exhaustive work, and we also have to define the factors which are to be excluded from the analyses. For example, regarding soil management [1], the delivery of

calculation of present value.) While defining the base model, the calculated surpluses and savings for each sector were defined as constant. After processing both the literature and the information from specialists, the next step was to change the goals by defining those intervals between which the parameters of the economic calculation can fluctuate, taking the sector's specifics into consideration. Using this data, we defined an optimist and a pessimist scenario, behind which lie the cost-savings, surpluses, and extra revenues attainable via precision farming. This way, the various intervals were sorted into two groups and the various items were sorted by category according to the scenarios and the technological expectations. As an example, during the cost calculation of the insecticides, the pessimist side lists the savings on the product, while the surplus costs due to using a better, more effective insecticide appears only on the optimist side. As it can be seen from the results below, the optimist scenario may become less relevant. We have to clear up what indirect effects the more effective insecticides have on the environment (externalities), since in this case, the points of evaluating social effects and their expression on the level of companies come into play, which may suggest that the use of the better insecticide is more desirable (Figure 2).

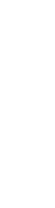

(1) 
technology processes we can use precision farming for. Based on the results of the analysis, we can also see that although this holds true, we need detailed yet selective information for material management and the machinery garages, meaning cost information broken down to sector element levels. Before we begin the data collection, we have to define the kinds of sector activities in the case of which the collection of information from the agronomical side is justified, as well as the hazards for which we can talk of cost savings in plant protection processes.

The results of the expanded model show that the size of precision farming also has a great level of influence on the return of the investment. The cost-benefit indicators of the model show a positive value in all values. However, the over-expectations of the technology show a great level of insecurity. This can primarily be seen in the fact that technology allows for the use of materials that don't have or have only slight detrimental effects on the environment altogether and also have a naturally higher cost. The offset of this is not present in the model. We can correct this problem using the "internalization" mentioned before, but the question comes up of how this can work from an economic viewpoint. Cover can be provided by two sides: either higher sales prices - supposing that a lesser level of insecticide use means higher quality on the product side - or the possible subsidies for protecting the environment. For the latter, we could define the support system of precision farming using the previously mentioned techniques. The bi-directional questions mentioned in the model calculations are already subjects of research, using which we can define the calculation methods of basic numbers, with which we can decide if a given area can be included into precision farming.

\subsection{Applicability of Cost-Benefit Analysis for Husbandry Sectors}

A DeLaval VMS automatic milking system was placed into operation in April, 2013 at Szent Istvan University's Experimental Farm, which has 100 cows. The automatic milking system replaced the $2 * 5$ milking position herringbone milking parlor that had been operating since 1996. The redesign of the parlor area was carried out before the automatic milking system was placed into operation, during which the equipment required for controlled herd management were installed. In addition, selection and control gates were installed, and the water supply system was also revamped. The investment totaled USD 202,907 net.

The goal of the analysis is to show the different kinds of economic processes and methods that can help the farmer in choosing between the different milking technologies.

In this analysis, the decision to invest in an automatic milking technology was made using the previously introduced calculation scheme of converting surplus income to present values, based on SZÉKELY (2000).

In our present calculation, the only items directly included are the ones in regard to which we gained actual practical experiences during the 5 month operation period. Additionally, the possible income from selling the previous milking parlor machinery was also excluded.

Regarding the total number of cows in the dairy farm, there was a need to implement a decrease of $10 \%$ since the ideal number of cows milked per day with the milking machine in question is 70 , which is less than the previous number of 90-100 cows kept in the farm. The drop in production due to the smaller number of cows (including the amount of produced milk and the number of calves) is USD 19,894. The increased income due to the technology transition calculated for 81 cows is USD 35,003, which is due to the annual increase in the amount of milk produced. The rise in income is partly due to a greater frequency of daily milking and partly because losses can be reduced with the new technology, including the turnaround time required for breeding. Due to the above, the time period between birthing two calves is shortened and the lactations of the cows is improved, thereby resulting in extra income.

The change in milking technology results in increased income, which consists of the following:

- electricity costs increased by $23 \%$, which equals USD 3,746 annually;

- supplement milking feed amounts to USD 7,261 annually due to surplus milk production;

- the DeLaval service pack (teat disinfection, chemical for somatic cell counting, maintenance service with parts) costs USD 10,058.

The change in milking technology results in increased cost savings, which consists of the following:

- wage savings amount to USD 21,347 annually if two persons caring for and milking the cows are laid off;

- feed costs decrease by USD 1,963 annually due to the smaller number of cows;

- the maintenance costs of the previous milking technology results in a USD 4,976 cost reduction annually.

Due to the smaller number of cows, a smaller area is required for the production of feed, which means 6.78 hectares can be used to grow crops for sale becomes possible after rearranging. A value of USD 110 was calculated as the surplus income resulting from the indirect economic effects of switching technologies. During the economic efficiency analysis of the investments, the analyzed time interval is 15 years and the calculative interest rate is $4 \%$. The return analyses were performed for two different investment strategies, which are the following:

$1^{\text {st }}$ case: $100 \%$ self-financed

$2^{\text {nd }}$ case: $40 \%$ subsidy intensity

Regarding the results of the cost-benefit analysis calculations, we have to keep in mind that the operation results of 5 months were commensurately extrapolated for a period of 1 year. During the calculations, the basic indices were defined as annuities due to the 1 year conversion.

The results can be summarized as follows. Based on the results of investment analyses done, we can establish that the introduced milking technology transition was valid from an economic point of view. When compared to the investment strategy which requires self-funding, the technology applying a $40 \%$ subsidy requires only half the time for a return on the 
investment, with doubled annual profits.

Table 2. C-B analysis of the milking robot investment of the Szent Istvan University Experimental Farm.

\begin{tabular}{|c|c|}
\hline \multicolumn{2}{|l|}{ Return on investment calculation } \\
\hline Time period & 15 years \\
\hline Calculative rate & $4.00 \%$ \\
\hline Subsidy intensity & $40.00 \%$ \\
\hline \multicolumn{2}{|c|}{ 1. Return on total cost of the development } \\
\hline NPV (or NEI) & USD 95520 \\
\hline Investment return time & 10 years \\
\hline$(\mathrm{r}-\mathrm{c}) \min$ & USD 8591 \\
\hline IPP & $9.10 \%$ \\
\hline \multicolumn{2}{|c|}{ 2. Return on capital costs and subsidies } \\
\hline Opportunity cost of capital & $4 \%$ \\
\hline NPV (or NEI) & USD 149618 \\
\hline Investment return time & 6 years \\
\hline$(\mathrm{r}-\mathrm{c}) \min$ & USD 13454 \\
\hline IRR & $16.90 \%$ \\
\hline \multicolumn{2}{|l|}{ Break-even point calculation } \\
\hline \multicolumn{2}{|c|}{ 1. Return on total cost of the development } \\
\hline Milking average (for 70 cows) & $23 \mathrm{~kg} /$ day $/ \mathrm{pc}$. \\
\hline The total daily amount of milk & $1620 \mathrm{~kg} /$ day \\
\hline C-B break-even differential value & $5 \mathrm{~kg} / \mathrm{day} / \mathrm{pc}$. \\
\hline
\end{tabular}

Source: self-made

The milk production required to reach the return of investment (break-even point) is $23.14 \mathrm{~kg} /$ day/individual, which means an approximate amount of $1620 \mathrm{~kg}$ of milk for the farm per day. To summarize, we can say that the decision maker also has to focus on the differences between systems when using this methodology (Table 2).

Questions on the practical application of the linear programming model results in establishing the production structure

The focus of these analyses is the development of agricultural enterprise production systems using a linear programming model. My prior experience shows that implementing the results of the optimal solution is usually impossible. This is because the Linear Programming (LP) model offers information on product structure proportions for the solution that only hold true in the case of a given cost-sales price proportion, and furthermore the decision maker doesn't get sufficient information on the field-level use of the solution. In our work, we evaluated the applicability of the calculated results and tried to determine the inherent obstacles. We also created a proposed solution on using the LP on the level of an agricultural field.

In order to make a clear and solvable initial table, we need prior analyses and to accept technical limitations when creating the LP model. The profession-related and methodology questions which surface and their answers are as follows:

1. Using the planning and operative information, the prior analysis and evaluation of resources has to be carried out. We have to identify the bottleneck resources. These resources can be evaluated with e.g. capacity-scale analysis, which can use e.g. the field registers or the tractor log as an initial data set.

The capacity-scale analysis is used to determine the prior resource quantities that were actually used. We can concentrate on pitting activities against each other during the creation of the initial table, in which resource allocation is high importance, and, with the use of the LP model, we can conduct further economic analyses and get new data to assist the evaluation in the case of the completely used up (exhausted) resources in the given interval (e.g. shadow price).

In case of agricultural enterprises, the time dimension of resources is of prominent importance. In the 1970's and 80's, so-called "campaign plans" were made for set intervals, in which the resource requirements of the individual one-year plans may not be sufficient for daily activities. In these cases, doing a pre-emptive, descriptive calculation for the interval may become handy, and including it in e.g. the target coefficient is possible, or it is also possible to create a time dimension that does not result in a drastic increase in the size of the initial table and it becoming too hard to interpret.

2. The steps of plant production have to be analyzed. Analyses which focus on activities have to be performed in a way so that the influences of sectoral activities on the enterprise's income appear either directly or indirectly together with the changes in production framework. The cost-analysis of the various activities may help with this decision. During the $\mathrm{ABC}$ analysis of costs, we can make assumptions on the grouping of the various costs and how well they can be planned. Items that result in costs that can not be automatically planned or that ate not impacting factors in defining the results can not be integrated into the LP model's table. The changes in economic value which are caused by these can be inserted into the actual plan after solving the LP. Regarding the remaining factors, the analysis in the model is fundamentally defined by which of the activity-related items that result in costs can be defined directly and which indirectly. The cases of directly calculated cost resulting items are quite simple, since their assumed values can be defined easily even prior to the activity. However, in cases of indirect costs, this is not as easy. The best example for this is to calculate the tractor plant's economic values and the method of accountability of applied labor as an activity. In this case, the problem is that the actual resource isn't maintained for the sake of one activity, since it is used by several activities, where the fact that the machine exerts different work amounts for the different activities comes into play as an additional problem. This is when the definition of the actual activity and the technique to settle its related costs comes into play. In the case of identical resources used for multiple activities, the different quantities also cause the differences in economic values defined in the target criteria. The question of the time dimension also comes up related to activities, since any given activity, if not done in the optimal time interval, may influence production. In these cases, a possible solution would be the creation of technology varieties, in the case of which we need to assume that some sector sections or activities are partly incorrectly performed, which obviously 
causes a decrease in income.

3. Using the problems in the previous points as a basis, the following solutions are available for their correction, according to the scale-criteria:

a. If there are many different types of resources, arranging them into groups helps. In this case, efficiency and effectiveness suffers a drawback, but manageability becomes easier. As an example, a solution in the case of the tractor plant includes grouping tractors into light, medium-heavy, and heavy classes. This means that the time-dimension of resources also becomes more manageable. This however modifies the prior step of planning a little, meaning that during the calculation of sectoral plans, the requirement changes from including resources to including groups. This also has the benefit of asset management decisions being differentiable from technological process decisions.

b. Grouping according to activities has to be managed in the scale criteria. This requires a prior analysis of activities, which includes both natural quantities and costs. In this case, we have the option of evaluating problems which are related to multipurpose programming since the economic values of all activities may be represented in the target criteria.

4. After Hungary's accession to the EU, we can mention several new factors that are barring impeding criteria to the production options of management. These don't always mean economically direct, displayable values. However, their evaluation is important since they often pose the narrow cross-section of activities, which, if uncontrolled, may lead to an increase in the efficiency of other resources (e.g. milk quota).

As we have already mentioned, using the results of the LP model directly is next to impossible. This is because the LP model is only applicable to a given cost-sale price range, and furthermore because the decision makers do not receive sufficient information regarding the results of the solution. The optimal production framework of the LP solution only tries to return the proportions of the different sectors which are represented in the plan. My experiences show that even if the field-level optimization model can be made, in this case - if we would like to consider all solutions - a matrix that is tailored to the product of the number of plants and number of fields in the initial table has to be made. The bigger the farm, and the more field parameters and activity types, the bigger the initial table will be. It is easy to see that in the conducting of an analysis on this scale, making mistakes both in the contents and physical ones during creating the LP becomes significantly easier, the correction of which consumes great amounts of time and effort.
Therefore, it is understandable that we question how the problem set could be easily solved. This is why we created a simulation method in the Szent Istvan University Experimental Farm, which offers a solution to this problem. As a first step, we accepted the results of the LP model, but only as size proportion markers [11]. This basically allows for the selection of solutions which resulted from the analysis, meaning that we tried to close the gap between solutions. This can be easily defined using the RN-function, if we link its value to the given sector, thereby adding crops to the various tables. The results we acquired underwent prior selection according to whether the solution included any sectors which were excluded from the LP. If there are, the solution can be rejected. Naturally, there is a possibility that the result we obtain from this is included, but in our evaluations, we disregarded these solutions.

In the next step, we have to examine whether the resulting solution is applicable to the other criteria. Among these, we have to highlight the following criteria:

- information which excludes crop rotation based on the crops grown on the given field in prior years,

- factors limiting production technology (e.g. ability to irrigate, isolation distance),

- bans resulting from prior use of materials (e.g. herbicides, integrated plant production, etc.),

- and last, but not least, the productivity values of crops grown on the given field.

To manage these criteria in the model, I created so-called banned fields, on the basis of which the above mentioned criteria can be automated and we can generate suboptimal solutions as the results of a simulation.

\subsection{The Complex Model Based on GHG Calculations}

In 2008-2009, we had the opportunity to do GHG balance analyses for eight large economies using the IPCC system related to an older IPCC study [8].

At that time, I basically only used methods for the analyses that rely greatly upon the so-called emission factors in the national GHG asset resources, which means that the model does not use data on an enterprise scale [9]. This led to the creation of the new model, which was applicable to the given systems and took their specific characteristics into account.

We linked the model based on the GHG calculation with the LP model, which is also useful for building complex analyses. This was necessary since the economy takes part in the Hungarian National Rural Network (HNRN), and we therefore had to consider its regulations in the criteria of crop rotation. These criteria were defined with the intern definition. Figure 3 shows the structure of the complex enterprise model. 


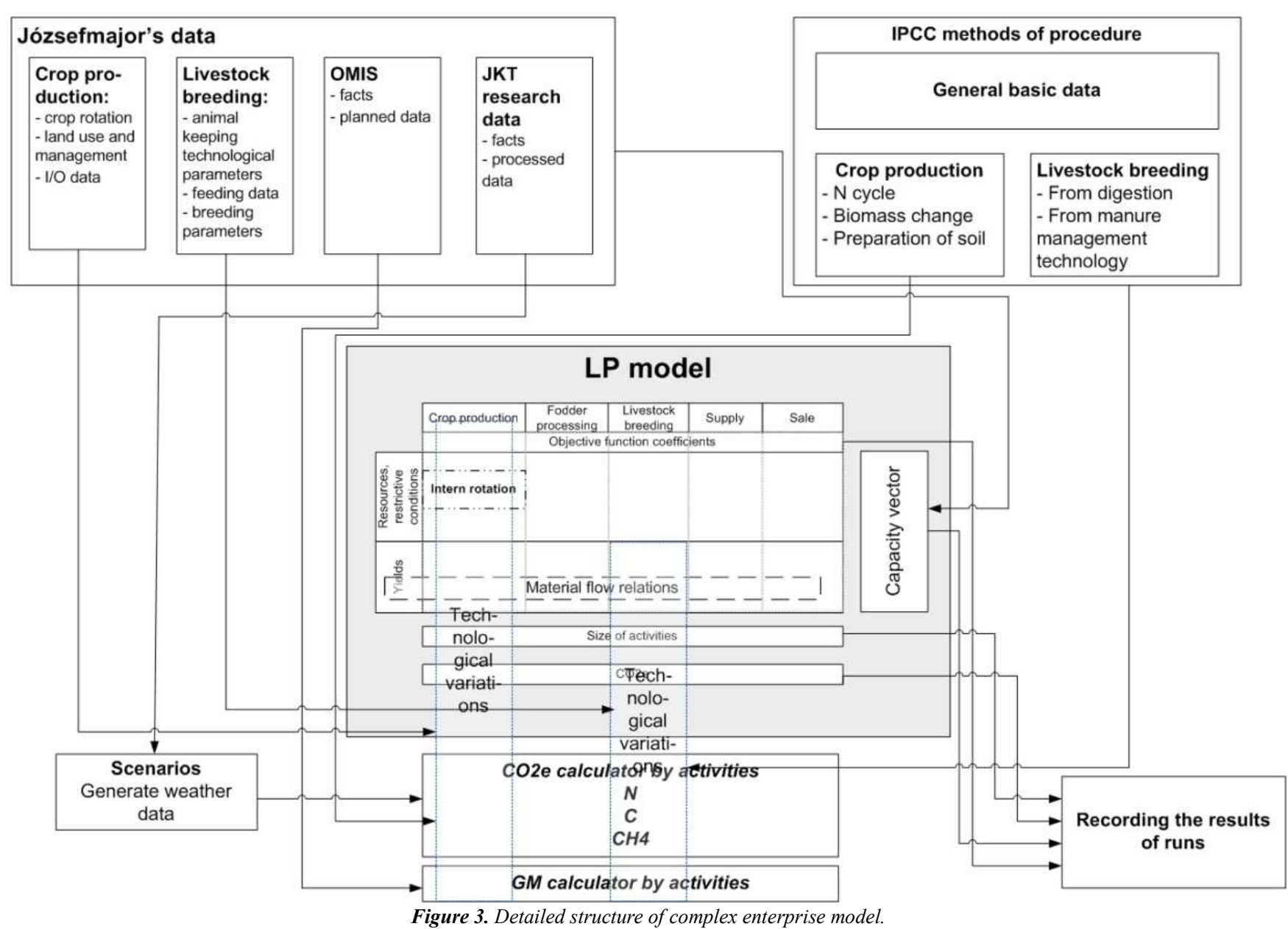

Source: self-made based on IPCC [7]; [8]

We also included the climate and its effect on production results into my analyses through the different development phases of the given crop culture. Using this relation and the research data of BIRKÁS (2002-2009), we generated the income effects of technological variations. These incomes have an effect on the results of the given sector and, as a result, on their carbon emission rates, in accordance with how the climate criteria are applied to which season's evaluation combinations of which scenarios.

In the case of the husbandry sector, the technological transition mainly affects the cows through milk production [10], feeding, and the related body mass changes. For this, we processed the unique body mass data received from the University Farm, catalogued from 2002 to 2009, with which calculating the need for feeding can be automated. Currently, this was set as a constant value in the model, but there is an available option to change it.

During the first executions of the model, as was foreseeable, changes in climate made up a separate combination space (Figure 3). These combinations were defined and the reduced number of model executions was performed after this. In summary, if we assume the scenarios of average and dry weather, the model was executed $2 * 81$ times (four seasons and three rainfall distributions). Figure 4 shows the results.

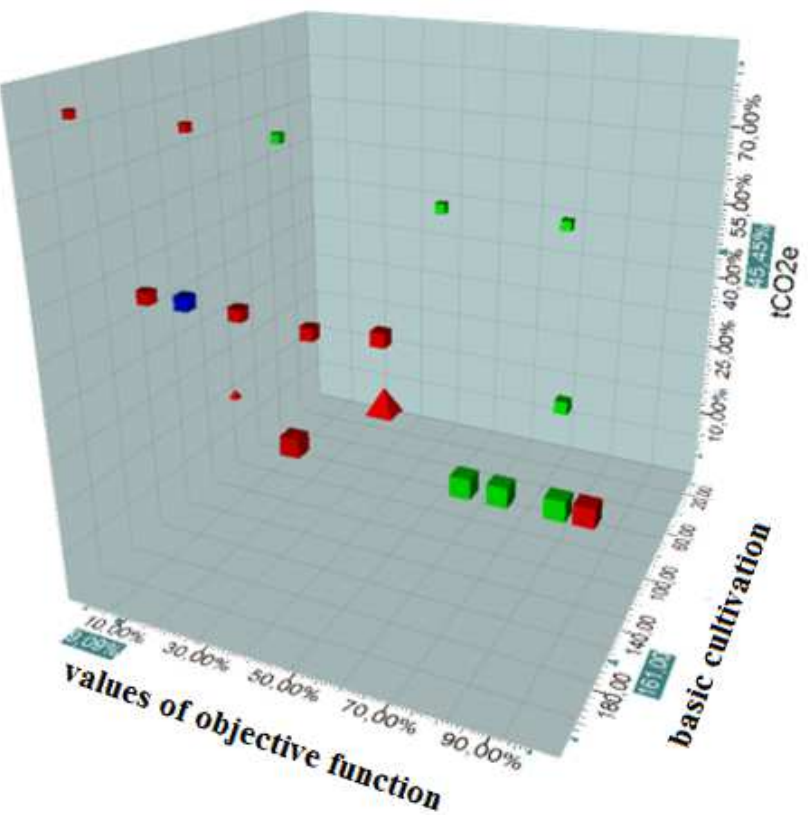

Figure 4. Results of model execution.

Source: self-made 
The red colors in the Figure indicate the climate conditions, while green indicates dryness. Cubes show the results of executions where the manure from the husbandry was used in its entirety for plant production (Figure 4). The size of the dot shows the final value of the goal function, while the results of the executions were placed on the axis according to percentage values. The rates of traditional and climate risk reducing plowing methods are indicated on the basic tillage axis.

\section{Conclusions}

Among the new and novel scientific results, we would like to draw attention to those that were already put into use at the University Experimental Farm and the results of which show their practical feasibility. The new and novel results are as follows.

1. The complex enterprise model developed on the basis of the GHG calculations revealed that, under variable climate conditions, combining different farming methods of plant production sectors is advised. This can furthermore be interpreted as a risk management method. The non-realized part caused by using this mixed structure is basically non-existent compared to what the farm can lose if they specialize in a single technology. Obviously, in case of climate conditions becoming favorable, the farm can realize a greater income, but this does not provide a solution to managing variables of various years.

2. The second result is that it is advisable to define the indicator we named 'surplus break-even point' during the cost-benefit analyses. This indicator offers information for the decision maker, which shows if the surplus value (income, cost reduction, improvement in production rate, etc.) of using a new technological process instead of the current production intensity is attainable or not. This means that the decision maker immediately gains information regarding the question of whether there is a need for drastic change and what part of the system should be changed to keep the farm functional.

3. We consider the following to be additional results:

a. The creation of the optimization method for LP in a breakdown per field, which helps with including the influences of pre-crops and the viability of growing the crop after itself (extern and intern definition is furthered with the banned fields).

b. The adaptability of the IPCC GHG calculation methods to the enterprise level and its applicability through a Hungarian example.
c. The introduction of $C$ - $B$ analyses and decision-centered cost-grouping into agricultural enterprise planning.

\section{Summary}

In our operational work, we frequently hear professionals ask why they have to plan and why they have to waste time with this activity as well. We believe our analyses show the main reason behind the importance of this question since, due to the complexity of agricultural systems, the decisions and factors which are not influenced by them are so numerous that the planner has a feeling of insecurity. Therefore, he disregards the documentation of this activity. And with this, he has already made the biggest mistake since this is not the way to generate a basis for comparison which may show the decision maker how the system works. The experiences of our past two decades show that without the document that results from documenting the planning, even the daily management questions lose their "compass", or in other words, the goals of the organizational criteria.

The workings of agriculture are inseparable from that of nature. Changes in nature demand a reaction from the farmer, or he has to deal with a loss of income, resulting in a threat to subsistence over the long term. Since many research programs have been initiated on technological solutions to negative environmental effects, the results of which have also been published, their economic confirmation becomes more important. Generally, we can still say that those who think in the short term still find traditional plowing methods better, but they have to face detrimental effects over the long term, which can only be subsequently compensated with decisive cost sacrifices, mainly in the form of melioration decisions.

Therefore, the analysis further stresses the importance of structure-based thinking, especially in this sector. This also leads to the requirement of deeper knowledge and trying different approaches. For example, to let the decision maker disregard the traditional grouping of costs, he has to be introduced to the advantages that use a slightly more complicated method to make later management processes easier and more effective.

The structure-based approach is supported by the development decisions based on cost-benefit analyses. On the one hand, these help in learning the decision-based cost grouping and, on the other hand, the decision maker will be capable of including the pros and cons of the prior and present states into his thinking as a result of the process-based thinking.

The analysis shows that Hungary has to improve the measurement and collection of the effects environmental changes. Sadly, due to the economic hardships of previous years, this area yielded negative decisions as well, meaning that the operations of numerous data collection systems were suspended due to a lack of funding (e.g. Hungarian Feed Database). However, there are an increasing number of publications and research topics worldwide that deal with this topic. As for the data of the University Experimental Farm, the next step could be repeating the analyses for different soil types, maybe even for different climates [2]. The latter would clear up if we have to separate Hungary into climatic regions (currently, the IPCC handles the country as a single region). The introduced complex model currently operates with the data of one given year, meaning it can not be used as a dynamic model in the sense that the model created for precision farming does. Therefore, one of the main 
development routes has to be in this direction. This development may make the interpretation of effects brought upon by changes in the soil [3] as one of the main carbon holders. A further development can be the advancement of husbandry onto a higher stage. Currently, there is no way to include the differences of various vintage feeds by digestibility, which in turn has an impact on the emissions from digestion and excretion in the energy calculations. Using the Pareto principle in agricultural systems shows the basic values of the method. These are: one, it helps navigate through the main factors fundamentally defining the system's operations, and two, it shows the importance of the regulatory factors of biological processes. The latter shows that even though vitamins and trace elements for example are not included in factors to be planned, they have to be viewed as elements that have a decisive impact on the results. This resonates with the essence of the Pareto principle, since the planning system has to be tailored to the factors which have an impact on the system's results, and not their levels. According to the performed analyses, it is advisable to use a variety of climate risk reducing plowing methods. Even though the yield of any single year might be less as a result, a higher income is realizable over the long term. Finally, another suggestion is that Hungary (an EU Member State) should, similarly to other countries, also develop a carbon emissions calculator for agricultural enterprises. This can become important later in projects aiming at reducing the emissions of the national asset resources. This may help standardize the methods and the required data.

\section{References}

[1] BRADY, N. C., WEIL, R. R. (2002): The Nature and Properties of Soils. 13th edition, Prentice Hall, New Jersey, ISBN 0-13-016763-0, p. 960

[2] BOTTLIK L, CSORBA SZ, GYURICZA CS, KENDE Z, BIRKÁS M. (2014): Climate challenges and solutions in soil tillage. Applied Ecology and Environmental Res., 12. 1. 13-23. http://aloki.hu/pdf/1201_013023.pdf
[3] FOGARASSY, C. (2012) Low-carbon economy. (in Hungarian: Karbongazdaság) L'Harmattan, Budapest, 2012 pp. 23-25

[4] FOGARASSY, C. - NEUBAUER, E. (2014): Water value and water resource evaluation in Hungary. In: Ugrósdy, G. - Molnár, J. - Szücs, I. (Edited by) The Evaluation of Natural Resources. Agroinform Publishing and Printing Ltd., Budapest, 2014 pp. $103-127$

https://www.scribd.com/doc/251719231/Evaluation-of-Natura 1-Resources-2014

[5] IPCC (2001) Good Practice Guidance and Uncertainty Management 4.94 in National Greenhouse Gas Inventories (p.4.54.) 2001

[6] IPCC (2006) Guidelines for National Greenhouse Gas Inventories. Volume 4, Agriculture, Forestry and other Land Use; Chapter 2-11. 2006

[7] IPCC (2009) Creating a model that calculates the emission rates of mixed-profile agricultural enterprises using the IPCC process, 2009.

[8] KOVÁCS, A. - HORVÁTH, B. - FOGARASSY, C. (2014): The influence of cultivation method on the soil's organic carbon content calculations (Hungarian SOC references values vs. IPPC de-faults). COLUMELLA Journal of Agricultural and Environmental Sciences Volume 2 (2014)

[9] http://www.columella.mkk.szie.hu/?menu=page32

[10] LENCSÉS, E. (2013): Different investment possibilities of the precision farming technology in Hungary In: Ubreziová I, Horska E (szerk.): Modern Management in the 21st Century Theoretical and practical issues. Nitra: Slovak University of Agriculture, pp. 208-220. (ISBN:978-80-89703-00-05)

[11] SZÉKELY CS., KOVÁCS A., GYÖRÖK B. (2000): The practice of precision farming from an economic point of view. Scientific Journal of Agricultural Economic, Special Edition, Vol. 13/1. pp. 56-65. http://gazdalkodas.hu/index.php?l=en\&p=szam\&szam_id=17

[12] SZÉKELY CS. (2009) Economic Effects of Climate Protection Measures. In: Palocz-Andresen M, Róbert Németh, Dóra Szalay (edit.) Támop-Humboldt College for Environment and Climate Protection 2009. December 3 and 2010. October 21 in Sopron University of West Hungary: Proceedings of the Conference „Protection of the Environment and the Climate”. p. 283 (ISBN:978-963-334-020-2) 